\title{
Space Technology for Decarbonising City Precincts
}

\author{
Jessica Bunning \\ Curtin University Sustainability Policy Institute, Curtin University, Perth, Australia \\ Email: jessbunning@hotmail.com
}

Received July 8, 2013; revised August 8, 2013; accepted September 8, 2013

Copyright (C) 2013 Jessica Bunning. This is an open access article distributed under the Creative Commons Attribution License, which permits unrestricted use, distribution, and reproduction in any medium, provided the original work is properly cited.

\begin{abstract}
Space technology is a powerful tool for climate research. Satellite data improve knowledge of the human impact on the Planet's physical geography. Similarly, remote sensing technology enhances understanding of the human impact on rising global carbon emissions. However, so far satellites have been principally limited to measuring the carbon emissions of cities from space. Standing alone, satellite technology is incapable of advancing the goal of decarbonisation. This will be achieved only if cities create local methodologies that significantly enhance the carbon reduction process. There exists enormous potential to bridge remote sensing for earth observation and global environmental change with local action towards decarbonised urban renewal and redevelopment. Satellite remote sensing has the ability to demonstrate if local remedial strategies are succeeding, and assist with planning, developing, and monitoring low and zero carbon infrastructure systems. Satellite-derived data can facilitate informed discussion and decision-making between community stakeholders to deliver low carbon outcomes at the precinct scale. Satellite-based systems can be integrated within the urban fabric to assist climate change mitigation. This paper is based on current work implemented jointly with municipalities to ascertain where within city precincts carbon emissions originate and how they can ultimately be reduced. It presents space technology as an instrumental tool for understanding the carbon impact of cities-in terms of the carbon intensive patterns and processes that shape human society, as well as having great potential for providing end-user products to communities to enhance the process of decarbonising city precincts.
\end{abstract}

Keywords: Carbon; Cities; Development; Remote Sensing; Satellite; Space Technology

\section{Decarbonising Growing Cities}

Many cities in the world are growing increasingly larger, evolving into megacities, hosting the densest populations that history has ever known. Fifty percent of the world's people now live in urban areas, and demographers predict that by 2050, 5.3 billion inhabitants, or $70 \%$ of the human race, will reside in cities [1]. These thriving megalopises require vast improvements in resource productivity, and resilient solutions for power, water and waste services that are more in sync with the environment [2]. Outdated, carbon intensive, city infrastructure systems are struggling to keep up with the pace at which cities are growing, and they are significantly contributing to rising global carbon emissions [3]. Humans need a new approach, a new way of thinking, and a new way of looking at how cities are designed, built and powered. Similarly, new management strategies are required that can support low and zero carbon technology options that aim to enhance people's lifestyles and create a cleaner Planet. Today, an opportunity exists to re-imagine, reinvent and reinvest in the world's cities to restore the Earth's natural balance and safeguard a future whereby the next generation can proudly take over its stewardship [4,5].

This process of namely, “decarbonisation” will involve redeveloping each urban precinct step by step with a lower carbon footprint. The urban and climate change challenge will not be solved with one quick fix. Offering up complex, location specific problems, solutions need to be found through communal and creative problem solving at the finer, precinct-scale level. Thus, decarbonising cities require all international, national, and local governments, non-governmental organisations, research institutes, universities, local communities, and the private sector to collaborate, share ideas, methodologies, knowledge and expertise [5].

Space agencies therefore, also have an important role to play in this process of decarbonising city precincts by contributing space technology. As the former US Vice President Al Gore advocates, "the historic effort to solve the climate crisis will require the innovative use of every new tool available [6]". If the world is to move towards a "green" economy, based on a circular flow of resources, 
then since all of society will be affected by this change; all sectors should contribute to its transformation, to enable its smooth transition.

\section{City Carbon Emissions}

As major centres of carbon intensive production and resource use, the world's expanding cities account for a large proportion of rising global carbon emissions. However, discrepancies exist in the reporting of exactly how much they contribute, with some reports overstating emission figures. On the one hand, World Energy Outlook 2008 claims that cities are responsible for $71 \%$ of worldwide emissions; on the other, the Clinton Climate Initiative states that they contribute 80\% [7]. Even more contradictory, the IPCC avers that cities are more likely responsible for between $30 \%$ and $40 \%$ of global carbon dioxide $\left(\mathrm{CO}_{2}\right)$ emissions [8].

This inconsistency reveals not only a degree of uncertainty about the precise quantity of carbon emissions but also a lack of agreement about with whom and where the responsibility lies for their production. For instance, factories located in semi-rural areas outside a city's boundaries are often the source of stationary energy consumed by city dwellers for their domestic and commercial purposes. However, these emissions are often excluded from the calculation of a city's total carbon footprint. Obviously, in order to determine the appropriate carbon mitigating actions required to moderate, reduce, or prevent the growth of carbon emissions, it is imperative to identify and measure the output of key sources for which a city is responsible.

\section{Satellites Measuring City Carbon Emissions}

Space agencies are helping to resolve some of the ambiguity surrounding the contribution of cities to global carbon emissions. Satellite technology is being deployed to assess city greenhouse gas emissions so that these emissions can be measured and monitored more accurately. The United States Defense Meterological Satellite Program (DMSP) uses an Operational Linescan System (OLS) to detect light emitted from the Earth's cities. As the lights are related to city energy production, the satellite can indicate the location of subsequent carbon emissions [9]. The European Space Agency (ESA) sensor, SCHIAM$\mathrm{CHY}$ (scanning imaging absorption spectrometer for atmospheric chartography) can identify trace gases, clouds, and dust particles throughout the atmosphere, which is useful for detecting high concentrations of methane emissions over industrial areas around the world [10]. China will launch their first Chinese carbon dioxide observation satellite (TanSat) in 2014, to monitor atmospheric carbon dioxide in Sun-Synchronous orbit with $\mathrm{XCO}_{2}$ precision of 1 - 4 ppm over regional scale [11]. NASA's Jet Propulsion Laboratory Megacities Carbon Project is measuring multi-year emission trends of carbon dioxide, methane $\left(\mathrm{CH}_{4}\right)$, and carbon monoxide (CO) attributed to several megacities and selected major sectors. After the pilot project's three year trial, NASA in coordination with its international partners, such as the Japan Aerospace Exploration Agency (JAXA), intends to expand the program to other cities [12].

Remote sensing, satellite technology is extremely useful for measuring city greenhouse gas emissions, and also for gaining a better perspective on the impact that the world's growing metropolises are having on global carbon emissions. However, the challenge is to account for those emissions generated outside a city's boundaries for which a city is nevertheless responsible, and which should be included in calculating its carbon footprint.

There exists enormous potential for these space satellite activities to be extended further to assist cities with the following: calculating the emissions inherent within the totality of city energy, water, and waste urban systems; providing guidance on which portions of carbon emissions cities should be responsible for mitigating; and with the planning, development and ongoing management of "on the ground" local carbon mitigating projects within precincts. This concept of linking "space with place" to help cities with reducing emissions, and balancing sustainability with resource management could potentially open up a whole series of new opportunities for decarbonised development.

\section{Calculating City Carbon Footprints}

A movement is growing internationally to measure the carbon impact of all urban developments and their associated infrastructure, including their energy supply, transport, buildings, water, and waste systems. More comprehensive data is needed regarding emissions from the material and construction processes involved in the built environment, the use of energy within buildings, the mode and use of transport, the operational energy required for distribution of electricity, gas, and water, and the management of waste [3]. Cities need assistance with acquiring quantifiable carbon data on these urban systems so they can ascertain where the bulk of their emissions are generated and devise appropriate strategies directed at those areas. Cities could benefit from greater access to remote sensing technology to help with assessing the emissions inherent in their urban systems that make up their total carbon footprint.

\section{Decarbonising City Precincts}

Enough discussion on sustainability issues has transpired over recent decades; now more action is needed for en- 
suring society's intelligent use of the Earth's natural capital. Similarly, cities are ready to progress from deliberating over ambitious carbon reduction goals; to realising carbon mitigation locally, that offers real consequences for improving "place”, and involving precinct communities in participating and investing in the process of decarbonised development.

For a shift in the economy, to low carbon to occur various scales of activity and innovation will be needed. There has been a lot of attention directed at reducing carbon emissions at the national level, and to a lesser extent at the building scale. However, far less notice has been given to low carbon construction at the precinct scale even though neighbourhoods are based on precincts, and new development within brownfield and greenfield areas are often planned at this finer scale [5].

Importantly, new low and zero carbon distributed networks for energy, water and waste are favoured by the precinct level, especially the use of: trigeneration and cogeneration (commonly known as combined heat and power or CHP); renewables such as photovoltaic systems, and small wind turbines; water recycling and wastewater treatment schemes; and waste to energy plants [13]. Such distributed systems are proving to be more resource efficient, less carbon intensive, and increasingly more economically viable than the conventional centralised approach to infrastructure and resource management [14]. Furthermore, precincts have been recognised as an excellent starting point, for demonstrating decentralised technologies operating successfully, and in turn gaining community support to raise capital to implement other low carbon development projects throughout the city [15].

\section{Remote Sensing Decarbonising Precincts}

An increasing unease over rising carbon emissions, energy and water security and expensive utility bills has incited greater interest from communities in the management of their local resources [15]. Parallel to this escalating community concern is municipalities are being handed greater responsibility for planning their precincts, and subsequently they need to be more transparent and accountable for major infrastructure decisions that affect the city's carbon footprint [5].

Municipal governments are no longer interested in solely measuring city carbon emissions; they are responding to a pressing need to re-examine urban infrastructure systems, identify key sources of carbon emissions inherent in the urban fabric, and reconstitute infrastructure networks accordingly to be less carbon intensive and more resource efficient.

Furthermore, the emerging precinct scale market for innovative low and zero carbon development is prompting local authorities to form strategic partnerships with a diversity of stakeholders in their community, including local business investors, organisations, and universities to build local capacity for investment in decarbonised development.

However, to make decarbonisation really work at a precinct level, precinct councils and their communities, require greater access to appropriate remote sensing tools for easing communication between stakeholders and making informed decisions and actions throughout the entire project planning and development process.

\subsection{Remote Sensing for Planning Precincts}

Insufficient technical and financial resources too often hamper local authorities' decision-making abilities and efforts to implement low or zero carbon development. Remote sensing software tools and applications that could perhaps help municipalities model or map various scenarios are often expensive, insufficient and not readily available at this scale. Or, Geographical Information Systems (GIS) technology is presented as a "black box" to protect commercial interests, so users have limited access to manipulating data, configuring scenarios and hence, being in control of making important assumptions linked with urban planning decisions.

Local authorities need remote sensing tools to help them identify where to prioritise their carbon mitigating actions and to understand the impacts and trade-offs of certain decisions, as well as the investment costs involved in choosing one strategy over another. For example, the majority of a precinct's emissions may be driven by unsustainable modes of transport or high-energy usage in commercial buildings. If a council can see that energy usage in a central business district drives the bulk of emissions, the council can then determine which energy efficiency measures will have the greatest effect in reducing its precinct's emissions. Municipal budgets often permit only one or two options for reducing carbon emissions, extending related actions over a period of several years; therefore, to gain trust and boost support for future projects, councils need to demonstrate a valuable outcome to the community.

Councils could also benefit from greater availability of remote sensing technology for assessing how precincts might evolve over time with certain staged planning decisions for low carbon development. This assessment includes the measurement of overall precinct emissions, the impact that infrastructure choices may have on local environmental resources, and the potential cost savings that may be realised for local government and the community by the implementation of any given choice. Greater use of drone imagery integrated within simple, easy-touse GIS modelling tools would enhance the visual platform and assist municipalities to better conceptualise, 
and thus understand the potential outcomes of certain modelled scenarios. Furthermore, improved visual platforms would enhance communication and participation of the wider stakeholder community in decision-making, including deliberate democracy and participatory budgeting processes.

\subsection{Remote Sensing for Monitoring Precincts}

Precinct communities need more sophisticated tools for monitoring low carbon construction, and evaluating its impact on the local area. Remote sensing technology holds great promise for accomplishing this goal.

Satellite derived data could facilitate documenting and visualising the local environment. Satellite imagery might detect changes from urbanisation that threaten to disrupt the resiliency of low or zero carbon infrastructure systems. Likewise, remote sensing drone technology could assist with determining the impact of green infrastructure design, for example, by measuring atmospheric temperatures to assess whether biophilic design landscaped along tall buildings reduces heat island effect of a precinct.

\section{Space Operating for Community Action}

Fostering greater collaboration between space agencies and municipalities with carbon-mitigating projects may well create win-win opportunities. Firstly, cities establishing strong linkages at finer scales between precincts and remote sensing agencies rather than with isolated, hierarchical and generalised governance agencies could open doors for municipalities to obtain the most relevant data to their specific local, urban and climate change challenges. Such issues are extremely location specific and complex, requiring many scales of intervention to handle effectively. If municipalities have greater access to remote sensing data, they will be better equipped to detect, quickly respond to, and deal with these local concerns in their context.

Secondly, local government often lacks the correct expertise to use remote sensing technology and understand the data. If local authorities and their precinct communities worked directly with space agencies, they could communicate more easily with remote sensing specialists and achieve a better understanding of the data. Enhanced understanding and knowledge at this level would help close the information gap, improve confidence, and ease the communication flow among all stakeholders involved in the delivery of precinct-level, low carbon solutions.

Local authorities and their precinct communities could in turn provide valuable on-the-ground information to improve the accuracy of space-satellite derived data, which can have limitations in measuring a city's carbon emissions and calculating its total carbon footprint.

Moreover, space agencies linking their space technolo- gies more with local places and community carbon mitigating actions, will undoubtedly generate appealing, attention-grabbing, tangible success stories for promoting the usefulness, relevance and important value of satellites for humanity.

\section{Space Technology Building Local Capacity}

All over the world, municipalities are being given both greater autonomy to respond to climate change, and flexibility to collaborate with organisations to build capacity for low carbon development [16,17]. At the precinct level in particular, municipalities are more in touch with the prerequisites for this development than the older utility providers operating on a much larger scale. Therefore, it makes sense that special attention be given to facilitating the way in which local councils implement and manage their infrastructure networks and mechanisms for service delivery [15].

Local authorities often lack the financial and technical means to accomplish the high sustainability goals envisioned by the community. So, forming partnerships with the private sector and civic society is fundamental to building their capacity for delivering decarbonised development $[5,18]$. If municipalities can demonstrate more clearly with remote sensing technology, the impacts of low carbon development, then communicating measurable, reportable and verifiable results will provide a more compelling argument to attract potential financial investors and gain acceptance from community stakeholders to initiate projects.

Increasingly, municipalities are working jointly with multiple actors on different levels to implement low carbon development. Partnering with the private sector, creating community ownership models, or involving residents in participatory budgeting are becoming more popular as tactics to attract financing, deal with management, and generate support for projects. Many organisations for example, pension funds and insurance companies are seeking to demonstrate a low carbon profile to their shareholders or board of directors through their investments and operations [18]. These actions are being taken as a result of good marketing decisions, genuine concern for the environment, and a desire to support innovation in the emerging green economy. Thus a strong incentive already exists for private sector engagement with the public sector, and both local government and precinct governance should profit from this interest.

\section{Conclusion-Linking Space with Place}

Just as urban areas are important drivers of national economies, urban infrastructure systems are the backbone of city economic, social, and environmental development. 
On the one hand, the pressures of urbanisation are placing great strains on existing city infrastructure systems, and on the other, the production, distribution, and consumption of city resources are significantly affecting the environment in negative ways, particularly with the increase in global carbon emissions. However, an opportunity exists now, during this time of rapid urbanisation, for cities to develop low carbon infrastructure systems. How cities choose their infrastructure today, including the technology and resource production and consumption patterns that shape people's lives, will ultimately determine the global carbon emissions of the future [7].

Cities need to invest in the construction and improvement of low carbon infrastructure systems not only to reduce their high carbon footprints but also to meet the demands of growing populations, and the need to remain competitive. Critical transport, power, water and waste systems must be upgraded and redesigned to achieve optimal functioning of services and efficient use of resources at minimal costs, and with the least impact on the environment. Identifying and calculating the carbon emissions inherent in city infrastructure systems and then redesigning less carbon intensive infrastructure networks is arguably the most important way in which to reduce cities' carbon emissions and thus their impact on the environment.

Decarbonising cities and subsequently their economies require many different kinds of innovation and activity. The process can be greatly assisted if precinct level, finer-scale development can be a focus, for precincts are where much new development is taking place and where distributed, low carbon systems can work effectively. Fortunately, new governance models are developing that allow precincts to operate with a degree of independence from central governments.

However, if precinct communities are going to have a substantial impact on reducing carbon emissions, they will need an innovative carbon governance model supported by and linked with the appropriate remote sensing technology. Well-planned cities matched with well-planned governance can help to reduce carbon emissions without sabotaging the population's quality of life. In fact, this combination of forces will enhance the way people live [15]. It will enable the transition to eco-city, focused on innovative urban design [19] and urban regeneration [20]. This new "green" economy or green urbanism [21], promises to present a new logic for urban development. Accompanied by decarbonised precinct infrastructure systems it will open up new job opportunities, provide clean air to breathe and fresh water to drink, public transportation will be more accessible and efficient, power bills will be lower, and active landfills will be replaced with flourishing green areas for food production and recreation.
In order to accomplish these things, city governments and their communities must have the appropriate tools for planning and developing their low carbon precincts. Remote sensing technology is one such tool; it can assist local authorities and their partners in planning, mapping, developing, and managing, operating, and monitoring low carbon precinct, infrastructure networks. Moreover, remote sensing holds enormous promise to enhance a municipality's ability to attract business people who are interested in investing in carbon-mitigating projects.

Working more closely with municipalities, space agencies can assist with converting carbon-sensing data into easily accessible and understandable information so that local authorities can make more informed, appropriate, and effective associated decisions. Similarly, "groundtruthing" activities, such as taking on the ground measurements to improve satellite data can be achieved in cooperation with local authorities working on local carbon-mitigating projects.

Developing better access to remote sensing tools that aid in the development of integrated, more efficient low carbon systems for the provision of energy, water, waste, and transport services will help cities not only reduce their overall impact on carbon emissions but also become more resilient to the impacts of climate change. These are actions that will affect the health of the biosphere for decades to come and thus define the moral responsibility of our generation.

\section{Acknowledgements}

The author would like to acknowledge the Australian Research Council for its financial support of the research behind this paper.

\section{REFERENCES}

[1] UN-HABITAT, "State of the World's Cities 2008/9Harmonious Cities,” Earthscan, London, 2008.

[2] E. Von Weizsacker, K. Hargroves, M.Smith, C. Desha and P. Stasinopoulos, "Factor Five: Transforming the Global Economy through 80\% Improvements in Resource Productivity,” Earthscan, London, 2009.

[3] C. Beattie, J. Bunning, J. Stewart, P. Newman and M. Anda, "Measuring Carbon for Urban Development Planning," The International Journal of Climate Change: Impacts and Responses, Vol. 3, No. 2, 2012, pp. 35-52.

[4] V. Rauland and P. Newman, "Decarbonising Australian Cities: A New Model for Creating Low Carbon, Resilient Cities," Proceedings of the 19th International Congress on Modelling and Simulation, MSSANZ, Perth, 12-16 December 2011, pp. 3073-3079.

[5] J. Bunning, C. Beattie, V. Rauland and P. Newman, "Low-Carbon Sustainable Precincts: An Australian Perspective,” Sustainability, Vol. 5, No. 6, 2013, pp. 23052326. http://dx.doi.org/10.3390/su5062305 
[6] A. Gore, "Our Choice-A Plan To Solve the Climate Crisis,” Rodale Press, New York, 2009.

[7] S. Dhakal, "GHG Emissions from Urbanisation and Opportunities for Urban Carbon Mitigation,” Sustainability, Vol. 2, No. 4, 2010, pp. 277-283.

[8] D. Satterthwaite, "Environmental Governance: A Comparative Analysis of Nine City Case Studies," Journal of International Development, Vol. 13, No. 7, 2010, pp. 1009-1014.

[9] C. Elvidge, M. Imhoff, K. Baugh, V. Hobson, I. Nelson, J. Safran, J. Dietz and B. Tuttle, "Night-time Lights of the World: 1994-1995,” ISPRS Journal of Photogrammetry and Remote Sensing, Vol. 56, No. 2, 2001, pp. 81-99. http://dx.doi.org/10.1016/S0924-2716(01)00040-5

[10] C. Frankenberg, J. Meirink, M. Weele, U. Platt and T. Wagner, "Assessing Methane Emissions from Global Space-Borne Observations,” Science, Vol. 308, No. 5724, 2005, pp. 1010-1014. http://dx.doi.org/10.1126/science.1106644

[11] Y. Liu, Y. DongXu and Z. Cai, “A Retrieval Algorithm for TanSat $\mathrm{XCO}_{2}$ Observation: Retrieval Experiments Using GOSAT Data,” Chinese Science Bulletin, Vol. 58, No. 13, 2013, pp. 1520-1523. http://dx.doi.org/10.1007/s11434-013-5680-y

[12] R. Duren and C. Miller, "Measuring the Carbon Emissions of Megacities," Nature Climate Change, Vol. 2, No. 8, 2012, pp. 560-562. http://dx.doi.org/10.1038/nclimate1629

[13] H. Ren and W. Gao, "A MLP Model for Integrated Plan and Evaluation of Distributed Energy Systems,” Applied Energy, Vol. 87, No. 3, 2010, pp. 1001-1014. http://dx.doi.org/10.1016/j.apenergy.2009.09.023
[14] CSIRO, "Intelligent Grid: A Value Proposition for WideScale Distributed Energy Solutions in Australia,” Commonwealth Scientific and Industrial Research Organisation (CSIRO), Newcastle, 2009.

[15] P. Newman and J. Kenworthy, "Sustainability and Cities,” Island Press, Washington DC, 1999.

[16] T. Tanner, T. Mitchell, E. Polack and B. Guenther, "Special Issue: Urban Governance for Adaptation: Assessing Climate Change Resilience in Ten Asian Cities,” Institute of Development Studies (IDS), Brighton, 2009, pp. 1-47.

[17] A. Duit, V. Galaz, K. Eckerberg and J. Ebbesson, "Governance, Complexity, and Resilience,” Global Environmental Change, Vol. 20, No. 3, 2010, pp. 363-368. http://dx.doi.org/10.1016/j.gloenvcha.2010.04.006

[18] A. Jones, "Chief Development Officer. Energy and Climate Change. City of Sydney. Interview by Jessica Bunning,” Tape Recording, Perth, Australia, 16 August, 2012.

[19] P. Newton, K. Hampson and R. Drogemuller, “Technology, Design and Process Innovation in the Built Environment,” Taylor \& Francis, Abingdon, 2009.

[20] P. Newton, S. Murray, R. Wakefield, C. Murphy, L. Khor and T. Morgan, "Towards a New Development Model for Housing Regeneration in Greyfield Residential Precincts,” Australian Housing and Urban Research Institute, Melbourne, 2011.

[21] P. Newton, P.Newman, S. Glackin and R. Trubka, “Greening the Greyfields: Unlocking the Redevelopment Potential of the Middle Suburbs in Australian Cities," World Academy of Sciences, Engineering and Technology, Vol. 71, 2012, pp. 138-157. 